\title{
BMJ Open Factors associated with disabling low back pain among nursing personnel at a medical centre in Japan: a comparative cross-sectional survey
}

\author{
Takahiko Yoshimoto (D) , ${ }^{1}$ Hiroyuki Oka, ${ }^{2}$ Shuhei Ishikawa, ${ }^{3}$ Akatsuki Kokaze, ${ }^{1}$ \\ Shingo Muranaga, ${ }^{3}$ Ko Matsudaira ${ }^{2}$
}

To cite: Yoshimoto T, Oka H, Ishikawa S, et al. Factors associated with disabling low back pain among nursing personnel at a medical centre in Japan: a comparative crosssectional survey. BMJ Open 2019;9:e032297. doi:10.1136/ bmjopen-2019-032297

- Prepublication history for this paper is available online. To view these files, please visit the journal online (http://dx.doi. org/10.1136/bmjopen-2019032297).

Received 12 June 2019 Revised 20 August 2019 Accepted 29 August 2019

Check for updates

(c) Author(s) (or their employer(s)) 2019. Re-use permitted under CC BY-NC. No commercial re-use. See rights and permissions. Published by BMJ.

${ }^{1}$ Department of Hygiene, Public Health and Preventive Medicine, Showa University School of Medicine, Shinagawa-ku, Japan ${ }^{2}$ Department of Medical Research and Management for Musculoskeletal Pain, The University of Tokyo, Bunkyo-ku, Japan

${ }^{3}$ Department of Rehabilitation, Kameda Medical Centre, Kamogawa, Japan

Correspondence to Dr Takahiko Yoshimoto; yoshimotota@gmail.com

\section{ABSTRACT}

Objectives Low back pain (LBP) is a common cause of disability among nursing personnel. Although many studies regarding the risk factors for LBP among nursing staff have focused on the physical load at work, multidimensional assessments of risk factors are essential to identify appropriate preventive strategies. We aimed to investigate the association of multidimensional factors (individual, physical, psychological and occupational) with disabling LBP among nursing personnel in Japan.

Design Observational study with comparative crosssectional design.

Setting Data were collected using the self-administered questionnaire at a tertiary medical centre.

Participants After excluding participants with missing variables, 718 nursing personnel were included in the analysis.

Outcome measures A self-administered questionnaire assessed individual characteristics, rotating night shift data, severity of LBP, previous episode of LBP, sleep problem, kinesiophobia (Tampa Scale for Kinesiophobia), depressive condition (K6), physical flexibility and frequency of lifting at work. A logistic regression model was used to evaluate the factors associated with disabling LBP (LBP interfering with work) among nursing personnel.

Results Of all participants, 110 (15.3\%) reported having disabling LBP. The multivariable logistic regression analysis after adjustment for several confounding factors showed that kinesiophobia (highest tertile, adjusted OR (aOR): 6.13 , $95 \% \mathrm{Cl}: 3.34$ to 11.27 ), previous episode of LBP (aOR: $4.31,95 \% \mathrm{Cl}: 1.50$ to 12.41 ) and insomnia (aOR: 1.66 , $95 \% \mathrm{Cl}: 1.05$ to 2.62$)$ were significantly associated with disabling LBP.

Conclusions The present study indicated that kinesiophobia, a previous episode of LBP, and sleep problems were associated with disabling LBP among nursing personnel. In the future, workplace interventions considering assessments of these factors may reduce the incidence of disabling LBP in nursing staff, although further prospective studies are needed.

\section{INTRODUCTION}

The global burden of disease study 2017 indicated that low back pain (LBP) is one of the leading causes of disability worldwide. ${ }^{1} \mathrm{LBP}$ is
Strengths and limitations of this study

- This study focused on disabling low back pain (LBP) as the outcome of interest, which was considered as a serious problem in workplace.

- This study was designed to assess simultaneously the multidimensional aspects (individual, physical, psychological and occupational) of disabling LBP among nursing personnel in Japan.

- This paper provides results that will be useful in understanding the complexity of LBP and developing appropriate strategies for reducing the incidence of occupational LBP.

- This study was conducted among participants at one medical centre, which might limit the generalisability of our findings.

- The cross-sectional design of this study could not clarify a causal relationship.

a major public health problem with an enormous negative economic impact on individuals, industries and societies. ${ }^{23}$

The aetiology of LBP is multifactorial and includes physical factors (physical load at work, ${ }^{4}$ physical flexibility ${ }^{5}$ and so on) and psychological factors (depression, ${ }^{6}$ fear-avoidance belief ${ }^{7}$ and so on). Among psychological factors, pain-related fear of movement/reinjury, which is known as kinesiophobia, has been suggested to be an important contributor for LBP. ${ }^{8}$ LBP also recurs frequently; thus, a previous episode of LBP can be a predictor of future episodes. ${ }^{9}$ Moreover, lifestyle factors including sleep problems can increase the risk of LBP. ${ }^{10}$

Several studies have shown that nursing personnel have a higher prevalence of LBP relative to the general population or other occupational groups, ${ }^{11-13}$ which may be related to nursing work-related factors. Indeed, in addition to the above physical and psychological factors, occupation-specific factors such as manual handling ${ }^{14} 15$ 
and rotating night shifts ${ }^{16}$ have been suggested to be associated with the development of LBP among nursing personnel. Because LBP could lead not only to decreased work performance, but also professional abandonment, ${ }^{18}$ clarifying the risk factors of LBP and exploring appropriate preventive strategies is essential to reduce the incidence of LBP among nursing professionals.

Although there is ample evidence showing that physical factors, including manual handling, among nursing personnel are a significant risk factor for $\mathrm{LBP}^{14}{ }^{15} 18$ systematic reviews of interventions for LBP in nurses have indicated that ergonomic interventions for LBP had inadequate results. ${ }^{19}{ }^{20}$ Thus, studies investigating the factors associated with LBP among nursing personnel from a multidimensional perspective including individual, physical and psychological factors are increasingly needed. Since the prevalence of disabling LBP varies across countries and occupations, ${ }^{21}$ it may be important to investigate the factors associated with disabling LBP among nursing personnel in Japan in order to design appropriate strategies for reducing the incidence of occupational LBP. Therefore, we aimed to perform a multidimensional assessment, including individual, physical, psychological and occupational aspects, of disabling LBP among nursing personnel at a tertiary medical centre in Japan.

\section{METHODS}

\section{Study populations}

This comparative cross-sectional study was based on a survey conducted among nursing personnel at Kameda Medical Centre at Chiba Prefecture, Japan, during February 2017. During this period, an anonymous, self-administered questionnaire was distributed to 1152 workers at the nursing department in the centre. After the workers answered the questionnaires, they put them in sealed envelopes. Then, occupational health staff collected and sent the envelopes to the authors. Staff other than the authors were not allowed to open the sealed envelopes. Written informed consent was obtained from each participant.

\section{Study measures}

The following items were assessed using the self-administered questionnaire: age, sex, height, weight, occupation type (registered nurse, assistant nurse, midwife or nursing aid), rotating night shift (frequency of shift work per month), severity of LBP, previous episode of LBP, sleep problem, fear-avoidance (kinesiophobia), depressive condition, physical flexibility and lifting at work. Body mass index (BMI) was calculated as weight $(\mathrm{kg})$ divided by the square of height $(\mathrm{m})$.

The severity of LBP, evaluated by respondents, was classified into four grades: grade 0 (no LBP), grade 1 (LBP that did not interfere with work), grade 2 (LBP that interfered with work) and grade 3 (LBP that interfered with work and required sick leave). These grades were determined with reference to Von Korff's grading method. ${ }^{22}$ The area of LBP (between the costal margin and inferior gluteal folds) was indicated as a diagram in the questionnaire. ${ }^{23}$ LBP was defined as pain lasting for $\geq 1$ day and experienced during the past 1 month, in accordance with the standard definition of LBP proposed by Dionne $e$ al ${ }^{24} \mathrm{LBP}$ associated with menstrual periods, pregnancy or febrile illness was excluded. Individuals with disabling LBP were defined as those who had LBP interfering with work, irrespective of sick leave because of LBP (grade 2 or 3). ${ }^{25}$ Past LBP history characteristics were evaluated in a question regarding the previous episode of LBP.

Sleep problems were assessed using questions about the sleep duration and sleep habits in the previous month. ${ }^{26}$ Disability of sleep duration was defined by durations $<6$ hours. Difficulty initiating sleep was defined as taking more than $30 \mathrm{~min}$ to fall asleep. Difficulty maintaining sleep and early morning awakening were defined by the occurrence of nocturnal awakenings or early morning awakenings three times or more per week. The presence of insomnia was defined if the participants reported at least one positive response to the three symptoms of sleep habits above. ${ }^{26}$

To assess fear of movement/(re)injury, we used the short version of the Tampa Scale for Kinesiophobia (TSK11). ${ }^{27}$ The TSK-11 consists of 11 items, each of which is scored on a 4-point Likert scale ranging from 1 (strongly disagree) to 4 (strongly agree). The total scores range from 11 to 44, with higher scores indicating greater fear of movement/(re)injury. The Japanese version of TSK-11 has been translated and validated by Matsudaira $e t a l .^{28} 29$ Participants' scores were classified into tertiles according to their total scores.

Depressive condition was evaluated using the Kessler 6-item psychological distress scale (K6) ${ }^{30}$ The K6 consists of six items that assess how frequently respondents experienced symptoms of psychological distress such as nervousness, negative affect, fatigue and worthlessness over the past 30 days. Each item was rated on a 5-point scale ranging from 0 (none of the time) to 4 (all of the time), with the total score ranging from 0 to 24 . The K6 has been translated to a Japanese version, whose reliability and validity have been confirmed by Furukawa et $a l^{31}$ Individuals with a $\mathrm{K} 6$ score of $\geq 10$ were defined as having a depressive condition in accordance with a previous study. ${ }^{32}$

Physical flexibility was assessed using the modified finger-to-floor distance ${ }^{33}$ which mainly represents trunk flexibility. The grade of this item was rated on a 7-point scale: (1) fingertips cannot reach across the knees; (2) fingertips can reach across the knees but not wrists; (3) wrists can reach beyond the knees, but fingertips cannot reach the ankles; (4) fingertips can reach the ankles; (5) fingertips can touch the floor; (6) all of the fingers can touch the floor; and (7) palms can touch the floor. Flexibility was classified into two groups based on whether wrists could reach beyond the knee, but fingertips could not reach the ankles. ${ }^{25}$ 
Physical work demand was measured with a question exploring the frequency of lifting at work. The frequency of lifting was divided into $0,1-4,5-9$ and 10 times per shift, and lifting $\geq 5$ times per shift was defined as frequent with reference to a previous study. ${ }^{16}$

\section{Statistical analysis}

We conducted a multivariable logistic regression analysis because our dependent variable (disabling LBP) was dichotomous. One guideline has suggested that a sample size with at least 10 cases for each independent variable is required to estimate a discriminant function parameters accurately in logistic regression analysis. ${ }^{34}$ Therefore, based on this guideline and our 11 predictor variables, we required 110 cases for our analysis. Moreover, considering the prevalence of disabling LBP and missing data, we calculated 1000 participants to ensure the accurate estimation in the analysis.

Data were presented as median (25th, 75 th percentile) for continuous variables or number (\%) for categorical variables. Characteristics of participants were compared using the chi-squared test for categorical variables and Wilcoxon rank-sum test for continuous variables. To assess factors associated with disabling LBP, a logistic regression model was used to estimate the OR and $95 \%$ CI for disabling LBP. In the model, the following factors were included for adjustment: sex, age, BMI, frequency of shift work, sleep duration, insomnia, previous episode of LBP, TSK and K6 scores, flexibility and lifting at work. Multicollinearity was not suspected as all variance inflation factors were $<2$. A p value less than 0.05 was considered to be statistically significant (two-sided). All statistical analyses were performed using JMP V.13.0 (SAS Institute).

\section{Patients and public involvement}

Patients and the public were not involved in the design or planning of the study.

\section{RESULTS}

Of all workers at the nursing department in the centre, 1075 respondents provided answers in the questionnaires (response rate: 93.3\%). Since the present study was focused on nursing personnel who provide direct care in the centre, 146 employees who were not related to direct nursing care (clerical work or providing guidance to patients and so on) were excluded. We further excluded 211 participants with missing data for any variable. As a result, 718 nursing staff completed the questionnaire with no missing data and were included in the analysis (completion rate: $66.8 \%$ ).

The median age of participants in the present study was 31.0 years, and $79.7 \%$ of the participants were female. The distribution of LBP severity according to grade was as follows: grade $0 \quad(n=233)$, grade $1 \quad(n=375)$, grade 2 $(\mathrm{n}=104)$ and grade $3(\mathrm{n}=6)$. Thus, $15.3 \%$ of the included participants were reported to have disabling LBP. The characteristics of participants with or without disabling
LBP are shown in table 1 . The proportions of insomnia $(\mathrm{p}<0.001)$ and previous episode of LBP $(\mathrm{p}<0.001)$ among participants with disabling LBP were higher relative to those observed in participants without disabling LBP. The proportions of those who had high TSK $(\mathrm{p}<0.001)$ or K6 $(p<0.038)$ scores were higher in the disabling LBP group than in the nondisabling LBP group. In contrast, the groups with and without disabling LBP showed no significant differences for physical flexibility and the frequency of lifting at work.

We calculated the crude and adjusted ORs and their 95\% CIs for disabling LBP (table 2). The non-adjusted analysis showed that insomnia, previous episode of LBP, and TSK and K6 scores were significantly associated with disabling LBP. Multivariable analysis after adjusting for sex, age, BMI and all explanatory variables showed that insomnia (adjusted OR (aOR): 1.66, 95\% CI: 1.05 to 2.62), a previous episode of LBP (aOR: $4.31,95 \% \mathrm{CI}$ : 1.50 to 12.41 ) and TSK score (aOR: $2.08,95 \%$ CI: 1.11 to 3.89 in middle, aOR: 6.13 , 95\% CI: 3.34 to 11.27 in high) remained significantly associated with disabling LBP.

\section{DISCUSSION}

The present study investigated the association of disabling LBP with related factors via a multifaceted assessment among nursing personnel at a tertiary medical centre. The results of our multivariable logistic regression analysis showed that insomnia, previous episodes of LBP and kinesiophobia were independently associated with disabling LBP. To our knowledge, this is the first study that identified a significant association of pain-related fear and insomnia with disabling LBP among nursing personnel in Japan.

In this study, disabling LBP was set as the outcome of interest to identify risk factors for LBP among nursing personnel. In occupational fields, absence from work (absenteeism) due to LBP is often used as the outcome of disability. However, the number of individuals taking a sick leave due to LBP is considerably small. A previous international epidemiological study showed that the prevalence of absenteeism due to musculoskeletal disorders, mainly LBP, was much less common in Japan relative to that in the UK. ${ }^{11}$ Moreover, it has been suggested that the loss of work performance due to LBP has a greater negative economic impact on individuals and workplaces in terms of healthcare costs and work productivity than sick leaves due to LBP. ${ }^{35}{ }^{36}$ Therefore, it may be appropriate to define disabling LBP as LBP interfering with work performance with or without sick leave.

Our results showed that high TSK scores were significantly associated with disabling LBP among nursing personnel after adjustment for various confounding factors (the OR (95\% CI) of the highest tertile of TSK: 6.13 (3.34 to 11.27)). This result was similar to those obtained in our previous studies with white-collar workers ${ }^{32}$ and workers at nursing care facilities, ${ }^{37}$ which implies that kinesiophobia is an important factor for LBP regardless of job 
Table 1 Characteristics of the study participants

\begin{tabular}{|c|c|c|c|}
\hline & $\begin{array}{l}\text { Disabling LBP } \\
(n=110)\end{array}$ & $\begin{array}{l}\text { Nondisabling LBP } \\
(\mathrm{n}=608)\end{array}$ & P value \\
\hline \multicolumn{4}{|l|}{ Sex } \\
\hline Female & $79(71.8 \%)$ & $493(81.1 \%)$ & \\
\hline Age, years & $27.5(24.0,40.0)$ & $31.0(24.0,42.0)$ & 0.052 \\
\hline Registered nurse & $88(80.0 \%)$ & $495(81.4 \%)$ & 0.886 \\
\hline Assistant nurse (practical nurse) & $2(1.8 \%)$ & $16(2.6 \%)$ & \\
\hline Midwife & $4(3.6 \%)$ & $18(3.0 \%)$ & \\
\hline Nursing aid & $16(14.5 \%)$ & $79(13.0 \%)$ & \\
\hline$<6$ hours & $32(29.1 \%)$ & $172(28.3 \%)$ & \\
\hline \multicolumn{4}{|l|}{ Insomnia } \\
\hline Not have insomnia & $47(42.7 \%)$ & $366(60.2 \%)$ & $<0.001$ \\
\hline Have insomnia & $63(57.3 \%)$ & $242(39.8 \%)$ & \\
\hline \multicolumn{4}{|l|}{ Previous episode of LBP } \\
\hline No & $4(3.6 \%)$ & $97(16.0 \%)$ & $<0.001$ \\
\hline Yes & $106(96.4 \%)$ & $511(84.0 \%)$ & \\
\hline \multicolumn{4}{|l|}{ TSK } \\
\hline \multicolumn{4}{|l|}{ Flexibility } \\
\hline Flexible & $75(68.2 \%)$ & $443(72.9 \%)$ & 0.314 \\
\hline Not flexible & $35(31.6 \%)$ & $165(27.1 \%)$ & \\
\hline \multicolumn{4}{|l|}{ Lifting } \\
\hline Not frequent & 45 (40.9\%) & $289(47.5 \%)$ & 0.2 \\
\hline Frequent & $65(59.1 \%)$ & $319(52.5 \%)$ & \\
\hline
\end{tabular}

Data are presented as number (percentage) or median (25th, 75th percentile).

LBP, low back pain; TSK, Tampa Scale for Kinesiophobia.

type. Kinesiophobia, an irrational and debilitating fear of movement/(re)injury, can cause a negative vicious cycle in the fear-avoidance model. ${ }^{38}$ Avoidance of behaviour based on kinesiophobia can cause physical inactivity, which has a negative impact on physical and psychological aspects and results in persistence of LBP. Werti et al reported that fear-avoidance beliefs were an important prognostic factor for LBP chronicity ${ }^{7}$ and predicted poor treatment responses in subjects with LBP of less than 6 months. ${ }^{39}$ Moreover, a recent systematic review has indicated that a greater degree of kinesiophobia at baseline predicted the progression of disability and the subsequent decline of quality of life among subjects with chronic musculoskeletal pain. ${ }^{40}$ Therefore, our results suggest that assessment of negative beliefs such as kinesiophobia may help prevent the chronicity of LBP in the workplace.

We found that the presence of a previous episode of LBP was a significant factor associated with disabling LBP, which is consistent with our earlier study in Japan. ${ }^{25}$ 
Table 2 Association between disabling low back pain and independent variables from logistic regression models

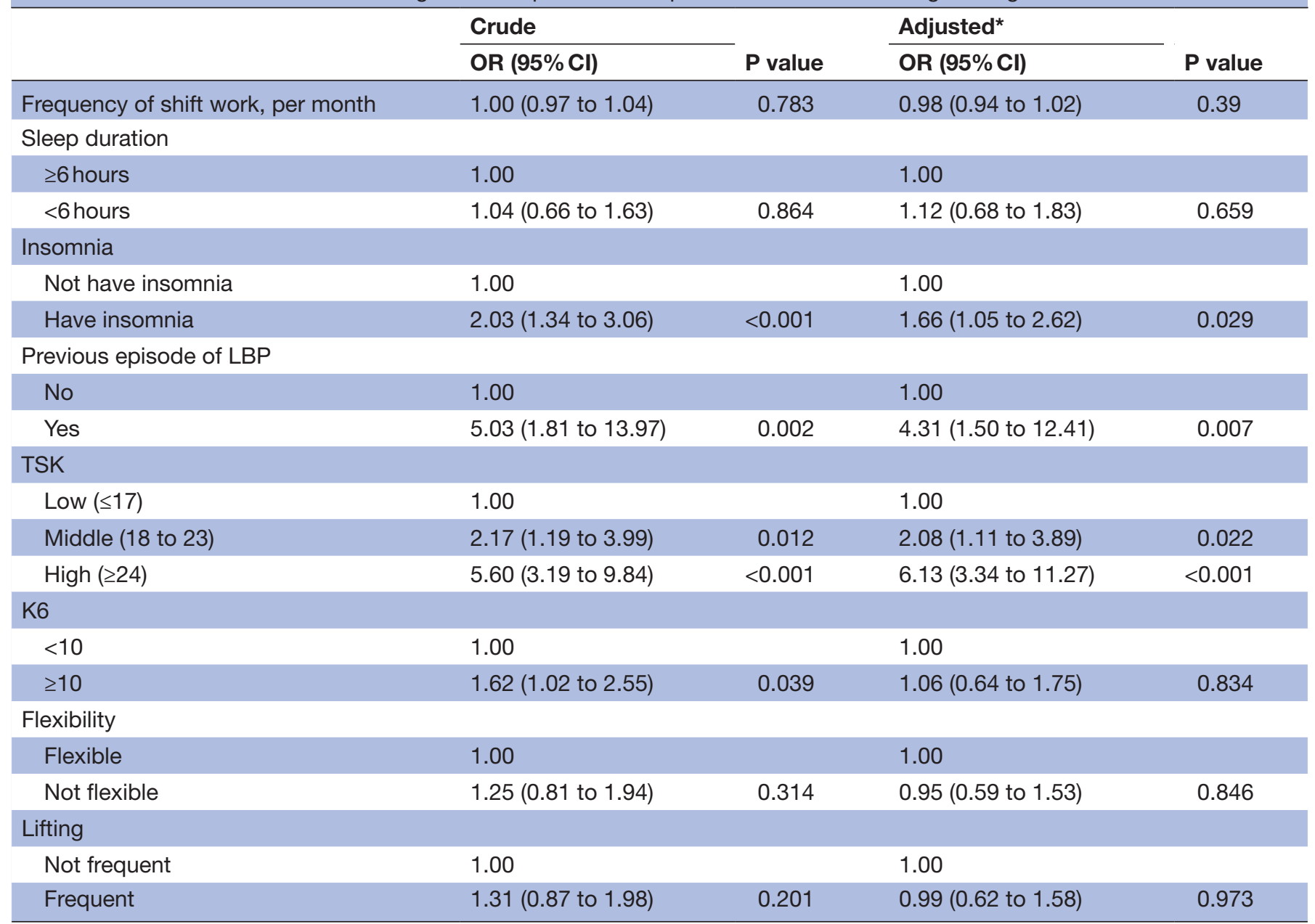

${ }^{*}$ Adjusted for sex, age, body mass index and all other variables which are indicated in this table.

LBP, low back pain; TSK, Tampa Scale for Kinesiophobia.

Previous systematic reviews also showed that individuals with a history of LBP were at increased risk of future episodes. ${ }^{941}$ Indeed, LBP has been suggested to be liable to recurrence. The recurrence rate of LBP, within the first year after the episode, has been reported to range from $24 \%$ to $50 \%$ or more. ${ }^{41}{ }^{42}$ This may be because individuals with LBP sometimes reduce their levels of physical activity, which leads to physical deconditioning, including functional changes of the trunk. A recent study indicated that trunk muscle mass was associated with LBP disability. ${ }^{43}$ Additionally, our results may indicate that individuals with LBP continue to have the risk factors responsible for the initial occurrence of LBP. Thus, a previous episode of LBP may be an important predictor of future episodes also among nursing personnel.

In this study, sleep disturbance defined as insomnia was found to be an independent factor relevant to disabling LBP among nursing personnel. Previous studies reported that more than $50 \%$ of those who suffer from LBP have sleep problems. ${ }^{44} 45$ Although the relationship between disturbed sleep and pain has been considered to be bidirectional, recent studies have focused on the influence of disturbed sleep on pain. Several prospective studies have indicated that sleep problems were associated with a higher risk of chronic musculoskeletal pain onset including LBP. ${ }^{10}{ }^{46}$ Our findings may be attributable to the decreased pain threshold consequent to sleep disturbance, which has been indicated by experimental studies. ${ }^{47}$ Although the mechanism underlying the association between sleep disturbance and pain remains to be fully understood, the mesolimbic dopamine system has been suggested to play a role via an overlapping neurophysiological mechanism between sleep and pain $^{48}$; however, because the potential mechanisms involved in these interactions are beyond the scope of our study, further studies including pathophysiological assessments are needed. Our results suggest that in the treatment of individuals with disabling LBP, assessment and management of both sleep problems and LBP may have more positive effects on recovery relative to those achieved by targeting sleep or LBP independently.

The present study investigated the association of disabling LBP with multidimensional factors among nursing personnel, including selective variables with reference to previous findings. These factors were assessed using validated tools, which would reduce the 
risk of classification bias. However, the study had some limitations. First, participants were recruited from a single medical centre, which might limit the generalisability of our results. Second, due to the cross-sectional design, the causality of the associations cannot be determined. Finally, our results might be affected by some potential confounding factors such as psychosocial work-related stress, other lifestyle habits or socioeconomic status that were not considered in our study.

In conclusion, the present findings obtained with a multivariable logistic regression analysis showed that kinesiophobia, previous episodes of LBP and insomnia were significantly associated with disabling LBP among nursing personnel. In the future, workplace interventions considering the assessment of these factors can help reduce the incidence of disabling LBP among nursing staff, although further prospective studies are needed to elucidate a causal relationship.

Acknowledgements We would like to thank Noriko Maruyama, Tsuyako Takanashi, Kyoko Yamamoto and all participants at the nursing department in Kameda Medical Centre for supporting the study.

\section{Contributors}

TY and KM contributed to the conceptualisation of this study. TY and SI contributed to the data acquisition. TY and $\mathrm{HO}$ analysed and interpreted the data. SM, AK and $\mathrm{KM}$ contributed to the supervision of this study. TY drafted the manuscript. All authors have read and approved the final manuscript.

Funding This study was supported by a grant from Industrial Disease Clinical Research Grants (No. 14020301). The funder had no role in study design, data collection and analysis, decision to publish, or preparation of the manuscript.

Competing interests KM reports grants from the Ministry of Health, Labor and Welfare during the conduct of the study; grants and personal fees from AYUMI Pharmaceutical Corporation, Nippon Zoki Pharmaceutical Co., Ltd., Ono Pharmaceutical Co., Ltd, Shionogi \& Co., Ltd., Eli Lilly Japan, Astellas Pharma Inc., Toto Ltd., Eisai Co., Ltd., Teijin Pharma Limited, Japan Inc., and Hisamitsu Pharmaceutical Co., Inc.; personal fees from Pfizer Inc., Janssen Pharmaceutical K.K., Kaken Pharmaceutical Co., Ltd., Mochida Pharmaceutical Co., Ltd., and Daiichi Sankyo Company, Limited; grants from Sompo Holdings, Inc., MTG, NuVasive Japan, and Murata Manufacturing Co., Ltd.; grants from Okamura Corporation; and nonfinancial support from Trunk Solution Co., Ltd. outside the submitted work.

Patient consent for publication Not required.

Ethics approval All procedures were approved by the Research Ethics Committee of Kameda Medical Centre (Approval No. 16-159) and carried out according to the Declaration of Helsinki.

Provenance and peer review Not commissioned; externally peer reviewed.

Data availability statement Data are available upon reasonable request.

Open access This is an open access article distributed in accordance with the Creative Commons Attribution Non Commercial (CC BY-NC 4.0) license, which permits others to distribute, remix, adapt, build upon this work non-commercially, and license their derivative works on different terms, provided the original work is properly cited, appropriate credit is given, any changes made indicated, and the use is non-commercial. See: http://creativecommons.org/licenses/by-nc/4.0/.

ORCID iD

Takahiko Yoshimoto http://orcid.org/0000-0002-3039-6179

\section{REFERENCES}

1. GBD 2017 Disease and Injury Incidence and Prevalence Collaborators. Global, regional, and national incidence, prevalence, and years lived with disability for 354 diseases and injuries for 195 countries and territories, 1990-2017: a systematic analysis for the global burden of disease study 2017. Lancet 2018;392:1789-858.
2. Dagenais S, Caro J, Haldeman S. A systematic review of low back pain cost of illness studies in the United States and internationally. Spine J 2008;8:8-20.

3. Dieleman JL, Baral R, Birger M, et al. US spending on personal health care and public health, 1996-2013. JAMA 2016;316:2627-46.

4. Hoogendoorn WE, van Poppel MN, Bongers PM, et al. Physical load during work and leisure time as risk factors for back pain. Scand $J$ Work Environ Health 1999;25:387-403.

5. Sadler SG, Spink MJ, Ho A, et al. Restriction in lateral bending range of motion, lumbar lordosis, and hamstring flexibility predicts the development of low back pain: a systematic review of prospective cohort studies. BMC Musculoskelet Disord 2017;18:179.

6. Pinheiro MB, Ferreira ML, Refshauge K, et al. Symptoms of depression and risk of new episodes of low back pain: a systematic review and meta-analysis. Arthritis Care Res (Hoboken) 2015;67:1591-603.

7. Wertli MM, Rasmussen-Barr E, Weiser S, et al. The role of fear avoidance beliefs as a prognostic factor for outcome in patients with nonspecific low back pain: a systematic review. Spine $J$ 2014;14:816-36.

8. Crombez G, Vlaeyen JW, Heuts PH, et al. Pain-related fear is more disabling than pain itself: evidence on the role of pain-related fear in chronic back pain disability. Pain 1999;80:329-39.

9. Taylor JB, Goode AP, George SZ, et al. Incidence and risk factors for first-time incident low back pain: a systematic review and metaanalysis. Spine J 2014;14:2299-319.

10. Mork PJ, Vik KL, Moe B, et al. Sleep problems, exercise and obesity and risk of chronic musculoskeletal pain: the Norwegian HUNT study. Eur J Public Health 2014;24:924-9.

11. Matsudaira K, Palmer KT, Reading I, et al. Prevalence and correlates of regional pain and associated disability in Japanese workers. Occup Environ Med 2011;68:191-6.

12. Leighton DJ, Reilly T. Epidemiological aspects of back pain: the incidence and prevalence of back pain in nurses compared to the general population. Occup Med (Lond) 1995;45:263-7.

13. Genevay S, Cedraschi C, Courvoisier DS, et al. Work related characteristics of back and neck pain among employees of a Swiss university hospital. Joint Bone Spine 2011;78:392-7.

14. Yassi A, Lockhart K. Work-relatedness of low back pain in nursing personnel: a systematic review. Int J Occup Environ Health 2013;19:223-44.

15. Burdorf A, Koppelaar E, Evanoff B. Assessment of the impact of lifting device use on low back pain and musculoskeletal injury claims among nurses. Occup Environ Med 2013;70:491-7.

16. Eriksen W, Bruusgaard D, Knardahl S. Work factors as predictors of intense or disabling low back pain; a prospective study of nurses aides. Occup Environ Med 2004;61:398-404.

17. d'Ettorre G, Vullo A, Pellicani V, et al. Acute low back pain among registered nurses. Organizational implications for practice management. Ann Ig 2018;30:482-9.

18. Schlossmacher R, Amaral FG. Low back injuries related to nursing professionals working conditions: a systematic review. Work 2012;41(Suppl 1):5737-8.

19. Dawson AP, McLennan SN, Schiller SD, et al. Interventions to prevent back pain and back injury in nurses: a systematic review. Occup Environ Med 2007;64:642-50.

20. Van Hoof W, O'Sullivan K, O'Keeffe M, et al. The efficacy of interventions for low back pain in nurses: a systematic review. Int $J$ Nurs Stud 2018;77:222-31.

21. Coggon D, Ntani G, Palmer KT, et al. Drivers of international variation in prevalence of disabling low back pain: findings from the cultural and psychosocial influences on disability study. Eur J Pain 2019;23:35-45

22. Von Korff M, Ormel J, Keefe FJ, et al. Grading the severity of chronic pain. Pain 1992;50:133-49.

23. Kuorinka I, Jonsson B, Kilbom A, et al. Standardised Nordic questionnaires for the analysis of musculoskeletal symptoms. Appl Ergon 1987;18:233-7.

24. Dionne CE, Dunn KM, Croft PR, et al. A consensus approach toward the standardization of back pain definitions for use in prevalence studies. Spine 2008;33:95-103.

25. Matsudaira $\mathrm{K}$, Konishi $\mathrm{H}$, Miyoshi $\mathrm{K}$, et al. Potential risk factors for new onset of back pain disability in Japanese workers: findings from the Japan epidemiological research of occupation-related back pain study. Spine 2012;37:1324-33.

26. Nakata A, Ikeda T, Takahashi M, et al. Sleep-related risk of occupational injuries in Japanese small and medium-scale enterprises. Ind Health 2005;43:89-97.

27. Woby SR, Roach NK, Urmston M, et al. Psychometric properties of the TSK-11: a shortened version of the Tampa scale for Kinesiophobia. Pain 2005;117:137-44. 
28. Kikuchi N, Matsudaira K, Sawada T, et al. Psychometric properties of the Japanese version of the Tampa scale for Kinesiophobia (TSK-J) in patients with whiplash neck injury pain and/or low back pain. $J$ Orthop Sci 2015;20:985-92.

29. Matsudaira K, Inuzuka K, Kikuchi N, et al. Development of a Japanese version of the Tampa scale for Kinesiophobia (TSK-J): translation and linguistic validation. Rinsho Seikei Geka 2013;48:13-19.

30. Kessler RC, Andrews G, Colpe LJ, et al. Short screening scales to monitor population prevalences and trends in non-specific psychological distress. Psychol Med 2002;32:959-76.

31. Furukawa TA, Kawakami N, Saitoh M, et al. The performance of the Japanese version of the K6 and K10 in the world mental health survey Japan. Int J Methods Psychiatr Res 2008;17:152-8.

32. Wakaizumi K, Yamada $\mathrm{K}$, Oka $\mathrm{H}$, et al. Fear-avoidance beliefs are independently associated with the prevalence of chronic pain in Japanese workers. J Anesth 2017;31:255-62.

33. Akaha $\mathrm{H}$, Matsudaira $\mathrm{K}$, Takeshita $\mathrm{K}$, et al. Modified measurement of finger-floor distance-Self-assessment bending scale-. J Lumbar Spine Disord 2008;14:164-9.

34. Katz MH. Multivariable analysis: a practical guide for clinicians. 2nd edn. Cambridge: Cambridge University Press, 2006.

35. Loeppke R, Taitel M, Richling D, et al. Health and productivity as a business strategy. J Occup Environ Med 2007;49:712-21.

36. Wada K, Arakida M, Watanabe R, et al. The economic impact of loss of performance due to absenteeism and presenteeism caused by depressive symptoms and comorbid health conditions among Japanese workers. Ind Health 2013;51:482-9.

37. Yoshimoto T, Oka H, Fujii T, et al. Survey on chronic disabling low back pain among care workers at nursing care facilities: a multicenter collaborative cross-sectional study. J Pain Res 2019;12:1025-32.

38. Leeuw M, Goossens MEJB, Linton SJ, et al. The fear-avoidance model of musculoskeletal pain: current state of scientific evidence. $J$ Behav Med 2007;30:77-94.
39. Wertli MM, Rasmussen-Barr E, Held U, et al. Fear-avoidance beliefs-a moderator of treatment efficacy in patients with low back pain: a systematic review. Spine J 2014;14:2658-78.

40. Luque-Suarez A, Martinez-Calderon J, Falla D. Role of kinesiophobia on pain, disability and quality of life in people suffering from chronic musculoskeletal pain: a systematic review. Br J Sports Med 2019;53:554-9.

41. Hestbaek L, Leboeuf-Yde C, Manniche C. Low back pain: what is the long-term course? A review of studies of general patient populations. Eur Spine J 2003;12:149-65.

42. Stanton TR, Henschke N, Maher CG, et al. After an episode of acute low back pain, recurrence is unpredictable and not as common as previously thought. Spine 2008;33:2923-8.

43. Hori $\mathrm{Y}$, Hoshino $\mathrm{M}$, Inage $\mathrm{K}$, et al. ISSLS Prize in clinical science 2019: clinical importance of trunk muscle mass for low back pain, spinal balance, and quality of life-a multicenter cross-sectional study. Eur Spine J 2019;28:914-21.

44. Hagen EM, Svensen E, Eriksen HR, et al. Comorbid subjective health complaints in low back pain. Spine 2006;31:1491-5.

45. Alsaadi SM, McAuley JH, Hush JM, et al. Prevalence of sleep disturbance in patients with low back pain. Eur Spine $J$ 2011;20:737-43.

46. Canivet $\mathrm{C}$, Östergren $\mathrm{P}-\mathrm{O}, \mathrm{Choi} \mathrm{B}$, et al. Sleeping problems as a risk factor for subsequent musculoskeletal pain and the role of job strain: results from a one-year follow-up of the Malmö shoulder neck study cohort. Int J Behav Med 2008;15:254-62.

47. Kundermann B, Krieg J-C, Schreiber W, et al. The effect of sleep deprivation on pain. Pain Res Manag 2004;9:25-32.

48. Finan PH, Smith MT. The comorbidity of insomnia, chronic pain, and depression: dopamine as a putative mechanism. Sleep Med Rev 2013;17:173-83. 